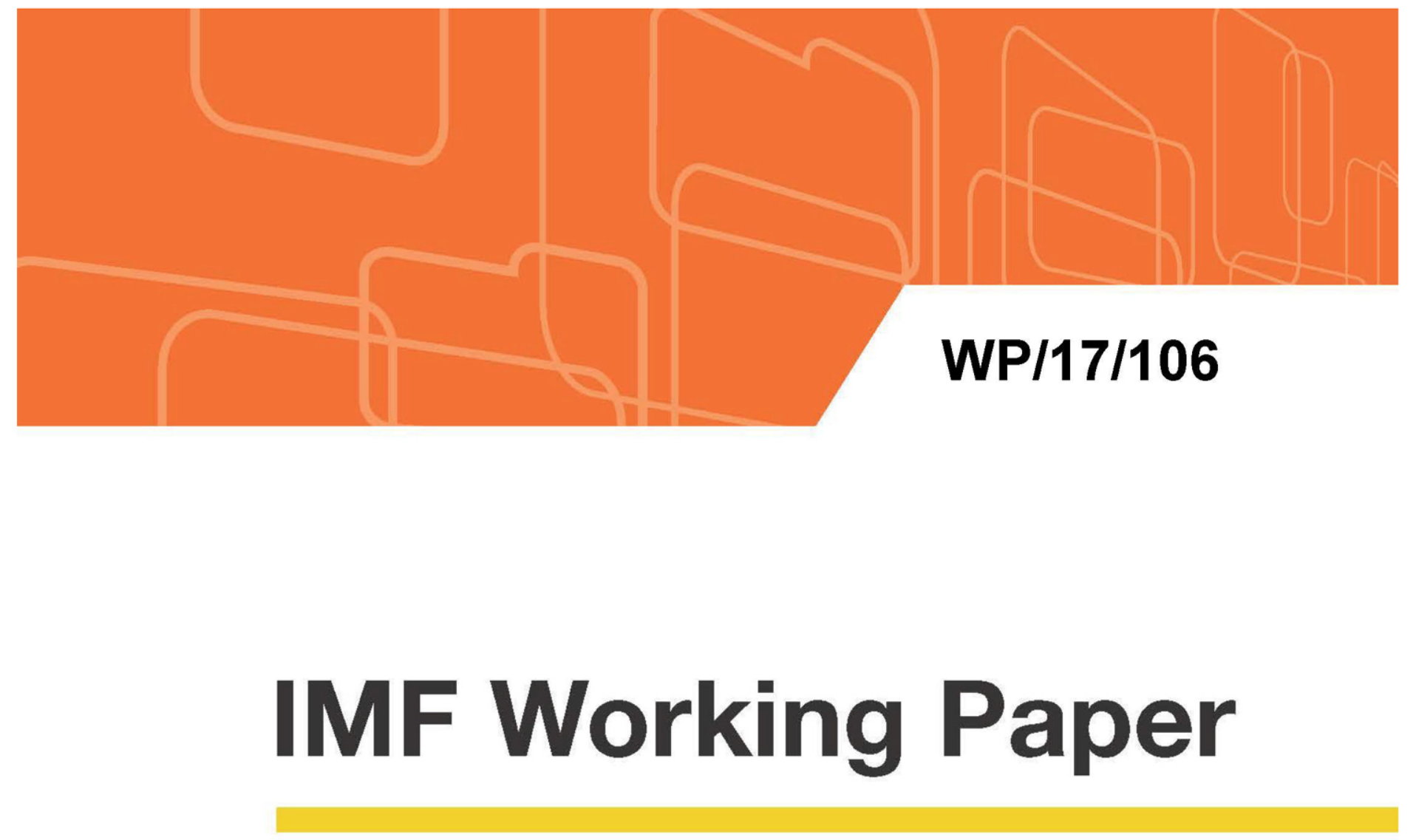

\title{
Multivariate Filter Estimation of Potential Output for the United States
}

by Ali Alichi, Olivier Bizimana, Douglas Laxton, Kadir Tanyeri, Hou Wang, Jiaxiong Yao, and Fan Zhang

IMF Working Papers describe research in progress by the author(s) and are published to elicit comments and to encourage debate. The views expressed in IMF Working Papers are those of the author(s) and do not necessarily represent the views of the IMF, its Executive Board, or IMF management.

I N T E R N A T I O N A L M O N 


\section{WP/17/106}

\section{IMF Working Paper}

\section{Multivariate Filter Estimation of Potential Output for the United States}

by Ali Alichi, Olivier Bizimana, Douglas Laxton, Kadir Tanyeri, Hou Wang, Jiaxiong Yao, and Fan Zhang

IMF Working Papers describe research in progress by the author(s) and are published to elicit comments and to encourage debate. The views expressed in IMF Working Papers are those of the author(s) and do not necessarily represent the views of the IMF, its Executive Board, or IMF management.

I N T E R N A T I O N A L M O 


\title{
IMF Working Paper
}

Research Department

\section{Multivariate Filter Estimation of Potential Output for the United States}

Prepared by Ali Alichi, Olivier Bizimana, Douglas Laxton, Kadir Tanyeri, Hou Wang, Jiaxiong Yao, and Fan Zhang ${ }^{1}$

May 2017

\section{IMF Working Papers describe research in progress by the author(s) and are published to elicit comments and to encourage debate. The views expressed in IMF Working Papers are those of the author(s) and do not necessarily represent the views of the IMF, its Executive Board, or IMF management.}

\begin{abstract}
Estimates of potential output are an important component of a structured forecasting and policy analysis system. Using information on capacity utilization, this paper extends the multivariate filter developed by Laxton and Tetlow (1992) and modified by Benes and others (2010), Blagrave and others (2015), and Alichi and others (2015). We show that, although still fairly uncertain, the real-time estimates from this approach are more accurate than estimates constructed from naïve univariate statistical filters. The paper presents illustrative estimates for the United States and discusses how the end-of-sample estimates can be improved with additional information.
\end{abstract}

JEL Classification Numbers: C51, E31, E52

Keywords: Macroeconomic Modeling, Potential Output

Author's E-Mail Address: AAlichi@imf.org; OBizimana@imf.org; DLaxton@imf.org; KTanyeri@,imf.org; HWang2@,imf.org; JYao@,imf.org; FZhang@,imf.org

\footnotetext{
${ }^{1}$ The estimates of potential output and the output gap presented in this paper are not official IMF estimates. The programs and potential output estimates can be downloaded from www.douglaslaxton.org. The authors would like to thank Yiqun Li for his excellent research assistance. All errors and omissions are our own.
} 


\section{Table of Contents}

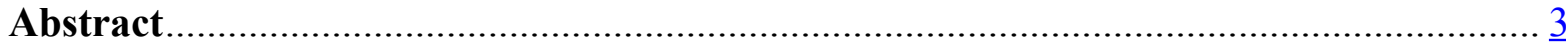

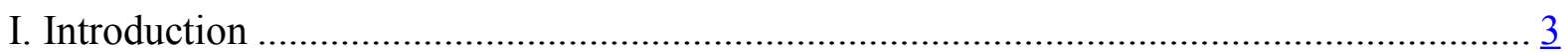

II. Potential Output-A Brief Overview of Common Estimation Techniques....................... $\underline{3}$

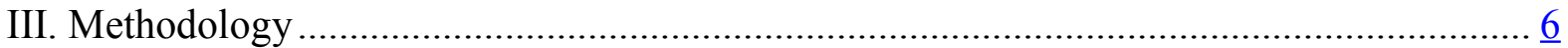

IV. Estimating the Output Gap For the United States .................................................. 10

V. Uncertainty in Estimating the Output Gap and Potential............................................ 15

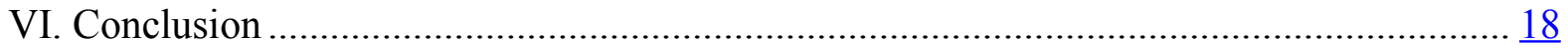

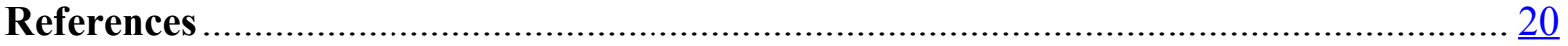

\section{Figures}

Figure 1. Shocks to the Level and Growth Rate of Potential Output, and to the Output Gap ...7

Figure 2. Output Gap Decomposition.........................................................................11

Figure 3. Output gap, Unemployment Gap, Capacity Utilization Gap, and Inflation .............12

Figure 4. 95-Percent Confidence Bands for Estimates of Potential Growth ..........................16

Figure 5. 95-Percent Confidence Bands for Estimates of Output Gap .................................17

Figure 6. Potential Growth Estimates as the Sample is Extended .......................................18

\section{Tables}

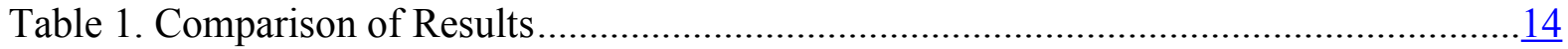

Table 2. Standard Deviation of Supply and Demand Shocks ............................................15

\section{Appendix Tables}

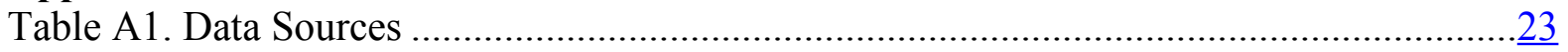

Table A2. Estimated Parameters .................................................................................. 23

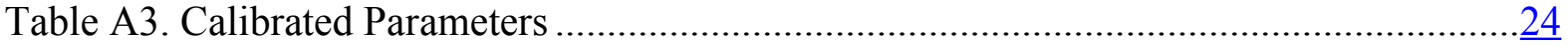




\section{INTRODUCTION}

This paper provides a re-examination of the multivariate filter (MVF) developed by Laxton and Tetlow (1992) and modified by Benes and others (2010), Blagrave and others (2015), and Alichi and others (2015). Using the Okun's (1962) definition of potential output, estimates of potential output and the output gap (defined as the percent deviation of actual from potential GDP) are estimated for the United States. There are several reasons why this technique is useful for analyzing the evolution of potential output and the output gap. First, the estimates of the output gap are economically plausible, with estimated periods of excess supply and demand coinciding closely with the priors of practitioners. Second, the filter includes some very basic economic identification restrictions - specifically the structure of the filter relates the output gap to slack in the labor market, and supply-shock adjusted measures of inflationary pressures. Third, the filter produces more stable real-time estimates of potential and the output gap relative to estimates from the Hodrick-Prescott (HP) filter, though a certain amount of uncertainty in real-time estimates is unavoidable. The multivariate filter performs well in the aftermath of financial crises, which tend to have significant scarring effects on the level of output and/or its growth rate. ${ }^{2}$ Finally, the results can be also adjusted in a transparent manner using information from outside of the model. This is particularly helpful at the end of the sample, given the uncertainty surrounding realtime assessment of economic slack. Still, it is important to note that the filter presented in this paper is designed to be the 'least bad' among a host of very mediocre choices - there is no panacea to the problem of estimating potential output in real time and users should feel free to impose their judgment based on additional information not included in the filter. That said, the multivariate filter estimates provide a very useful starting point for any analysis and impose some discipline on the estimation process.

The remainder of the paper begins with a brief review of the concept of potential output (Section II), contrasting it with concepts of 'sustainable' output recently discussed in the literature, as well as techniques commonly used to estimate potential. Section III presents the methodology used in this paper; detailed results are presented for the U.S. in Section IV. Section V presents confidence bands surrounding the estimates of potential output using the multivariate filter, and compares them to those from an HP filter. Section VI concludes.

\section{Potential Output-A Brief Overview of Common Estimation Techniques}

Potential output is generally thought of as the maximum level of output that an economy can sustain without generating inflationary pressure (Okun, 1962). This definition is particularly prevalent among monetary policy makers, as it allows them to communicate their policy

\footnotetext{
${ }^{2}$ See, for example, Chapter 3 of the April 2009 World Economic Outlook, which analyses the short-term dynamics of output following financial crises and Abiad and others (2009) who investigate the medium-term dynamics of output following banking crises.
} 
stance in the context of the short-run tradeoff between output and inflation. ${ }^{3}$ It is of critical importance that we be concrete in defining the concept of potential output, as this will shape how potential, and the corresponding output-gap estimates, are used by policy makers.

Although many practitioners approach potential output with the Okun's definition in mind, some recent work has focused on expanding or altering this definition to include consideration of macroeconomic imbalances more broadly (see Alberoa, Estrada, and Santabarbara (2013)), as well as financial imbalances in particular (see Borio, Disyatat, and Juselius (2013)). These measures are perhaps best thought of as gauging the path of sustainable future output, rather than current potential output (in the inflation/output tradeoff sense). More specifically, these sorts of imbalances may be used to 'signal' the risk of a future disorderly adjustment wherein output would be substantially lower for a period of time - both the timing of such an adjustment, and whether one would ultimately occur, is very uncertain. For example, in the case of financial-sector imbalances, a strong increase in credit growth and property prices often precedes a financial crisis (Benes, Kumhof, and Laxton, 2014a and 2014b). However, there is no a priori reason why rapid credit growth needs to be unsustainable - this sort of credit expansion could equally well be the product of sound economic fundamentals. Given the difficulty of identifying the drivers of a credit expansion in real time, it would not be wise to counsel policy makers to treat all such expansions as bad; rather, these sorts of expansions should be considered carefully, and treated as increasing the (downside) risks around a given baseline. As such, we view approaches which consider financial-sector and broader macroeconomic imbalances as complements to - rather than substitutes for-the Okun's concept of potential output. ${ }^{4}$

One of the more prevalent techniques to estimating potential is the use of univariate statistical filters, such as the HP filter, to smooth out fluctuations in output. The appeal of this approach is that it is simple, transparent, and can be applied to any country where GDP data exist. Unfortunately, the approach's relative simplicity brings with it several notable limitations. Chief among these is that the estimates are better thought of as 'trend' (rather than potential) growth, since these filters do not incorporate any economic structure, and thus are not consistent with an economic concept of potential - univariate filters represent a purely statistical approach to approximating potential output. In addition, the estimates which come out of these filters will reflect several statistical features which may be undesirable. For example, given that such estimates are based on measures of central tendency, the historical mean value of the output gap will tend to be biased toward zero, and the relative volatility of the cyclical vs. structural component will be determined by the selection or estimation of a

\footnotetext{
${ }^{3}$ For an example of how this tradeoff is communicated, see Bank of Canada (2009).

${ }^{4}$ See, for example, Benes, Kumhof, and Laxton (2014a and 2014b), which assesses vulnerabilities associated with excessive credit expansions and asset price bubbles, and the consequences of different macro-prudential policies or Rabanal and Sanjani (2015), which discusses the role of financial variables in computing the output gap.
} 
smoothing parameter. Finally, univariate filters suffer from a particularly acute 'end-ofsample' problem, with estimates towards the end of a given sample period being subject to significant revisions as more data ultimately become available and the sample is extended.

Another common technique to estimating potential output is the production-function approach, in which the inputs of production are considered separately. In its simplest form, this entails specifying a two-factor production function (generally Cobb-Douglas), obtaining data on employment and the capital stock, and then calculating total-factor productivity (TFP) as the residual from the production-function equation. By smoothing the resulting TFP series, and specifying a process for 'potential' employment, one arrives at an estimate for potential output by combining these trends with the estimate of the capital stock. ${ }^{5}$ This approach has the benefit of allowing for a more detailed examination of the drivers of potential. However, there are also limitations; in particular, reliable capital-stock data can be hard to obtain, and the estimates of potential arising from this approach are only as good as the filters used to de-trend the TFP and employment components. ${ }^{6}$

Furthermore, a good deal of work has focused on the use of multivariate filters to estimate potential (see Laxton and Tetlow (1992), Kuttner (1994), and more recently Boone and others (2002), Basistha and Startz (2008), Benes and others (2010), Fleischman and Roberts (2011), among others). This approach adds economic structure to estimates by conditioning them on some basic theoretical relationships (such as a Phillips curve relating the inflation process to the output gap). One strength of this approach is that estimates of the output gap and potential are consistent with the Okun's concept of potential. In addition, in its simplest form this technique is relatively easy to implement requiring only a few variables, and it can be augmented where data availability permits (see for example Alichi (2015)). Another advantage of the multivariate filter is that the estimates may not deviate too much from actual data, which helps capture shocks that may have lasting effects on the economy and leads to swift revisions of potential output. These features make the multivariate filter particularly useful for measuring potential output in the aftermath of the global financial crisis and the euro area sovereign debt crisis, for example, to the extent that these have had scarring effects on the level of output and/or its growth rate. The shortcomings of the multivariate-filter approach are similar to those facing other methods - there remains an important end-ofsample problem, and the estimates of potential and the output gap are only improved relative

\footnotetext{
${ }^{5}$ For an example of how the production-function approach can be implemented, see D'Auria and others (2010).

${ }^{6}$ As an example, if the employment and TFP series are de-trended using an HP filter, then the resulting estimates of potential output will have almost identical properties to those arising from a direct HP filtration of GDP data.
} 
to a simple statistical filtration if the structural relationships specified in the filter are valid in the economy in question. ${ }^{7}$

Yet another technique which is gaining popularity in recent years is the use of DSGE models to estimate potential and the output gap (see, for example, Vetlov and others (2011)). This approach is theoretically rigorous, and is thus particularly appealing to academic audiences. Unfortunately, this technique is very difficult to implement, requiring extensive modeling expertise and a great deal of time and effort. In addition, estimates of the output gap and potential output derived from these models tend to be particularly sensitive to the specifications of the DSGE model being used, and they are not always intuitive. This is problematic for policy makers who want to use these estimates to formulate policy. ${ }^{8}$

\section{Methodology}

The multivariate filter approach specified in this paper is relatively simple, requiring data on just a few observable variables. The four core variables of the model require data on GDP, the CPI, the unemployment rate, and the capacity utilization rate in the manufacturing sector. We measure the data at annual frequency to help deal with the noise in higher frequency quarterly data. In addition, we use data from consensus forecasts on near-term annual CPI inflation and longer-term real GDP growth to help better identify supply and demand shocks and if the shocks to potential are affecting the underlying growth rate of potential or just the level. In this section, we present the equations which relate these three observable variables to the latent variables in the model. Parameter values and the variances of shock terms for these equations are estimated using Bayesian estimation techniques and are provided in the appendix.

In the model, the output gap is defined as the deviation of real GDP, in log terms $\left(Y_{t}\right)$, from its potential level $\left(\bar{Y}_{t}\right)$ :

$$
y_{t}=Y_{t}-\bar{Y}_{t}
$$

The stochastic process for output (real GDP) is comprised of three equations, and subject to three types of shocks:

$$
\bar{Y}_{t}=\bar{Y}_{t-1}+G_{t}+\varepsilon_{t}^{\bar{Y}}
$$

\footnotetext{
${ }^{7}$ In addition, filtered estimates are usually based on a linearized version of the Phillips curve. For a discussion of nonlinearities and their related policy implications see Laxton, Rose and Tetlow (1993), Laxton, Ricketts and Rose (1993), Debelle and Laxton (1997), Isard, Laxton and Eliasson (1999), Clark, Laxton and Rose (1995, 2001), Argov and others (2007) and Alichi and others (2009).

${ }^{8}$ See Juillard and others (2007) and Vetlov and others (2011) for a discussion of issues related to measuring potential output from DSGE models.
} 


$$
\begin{aligned}
& G_{t}=\theta G^{S S}+(1-\theta) G_{t-1}+\varepsilon_{t}^{G} \\
& y_{t}=\phi y_{t-1}+\varepsilon_{t}^{y} \\
& G R O W T H_{t}=Y_{t}-Y_{t-1}
\end{aligned}
$$

The level of potential output $\left(\bar{Y}_{t}\right)$ evolves according to potential growth $\left(G_{t}\right)$ and a levelshock term $\left(\varepsilon_{t}^{\bar{Y}}\right)$. Potential growth is also subject to shocks $\left(\varepsilon_{t}^{G}\right)$, with their impact fading gradually according to the parameter $\theta$ (with lower values entailing a slower adjustment back to the steady-state growth rate following a shock). Finally, the output gap is also subject to shocks $\left(\varepsilon_{t}^{y}\right)$, which are effectively demand shocks. ${ }^{9}$ The role of each shock term is expressed graphically in Figure 1:

\section{Figure 1. Shocks to the Level and Growth Rate of Potential Output, and to the Output Gap}

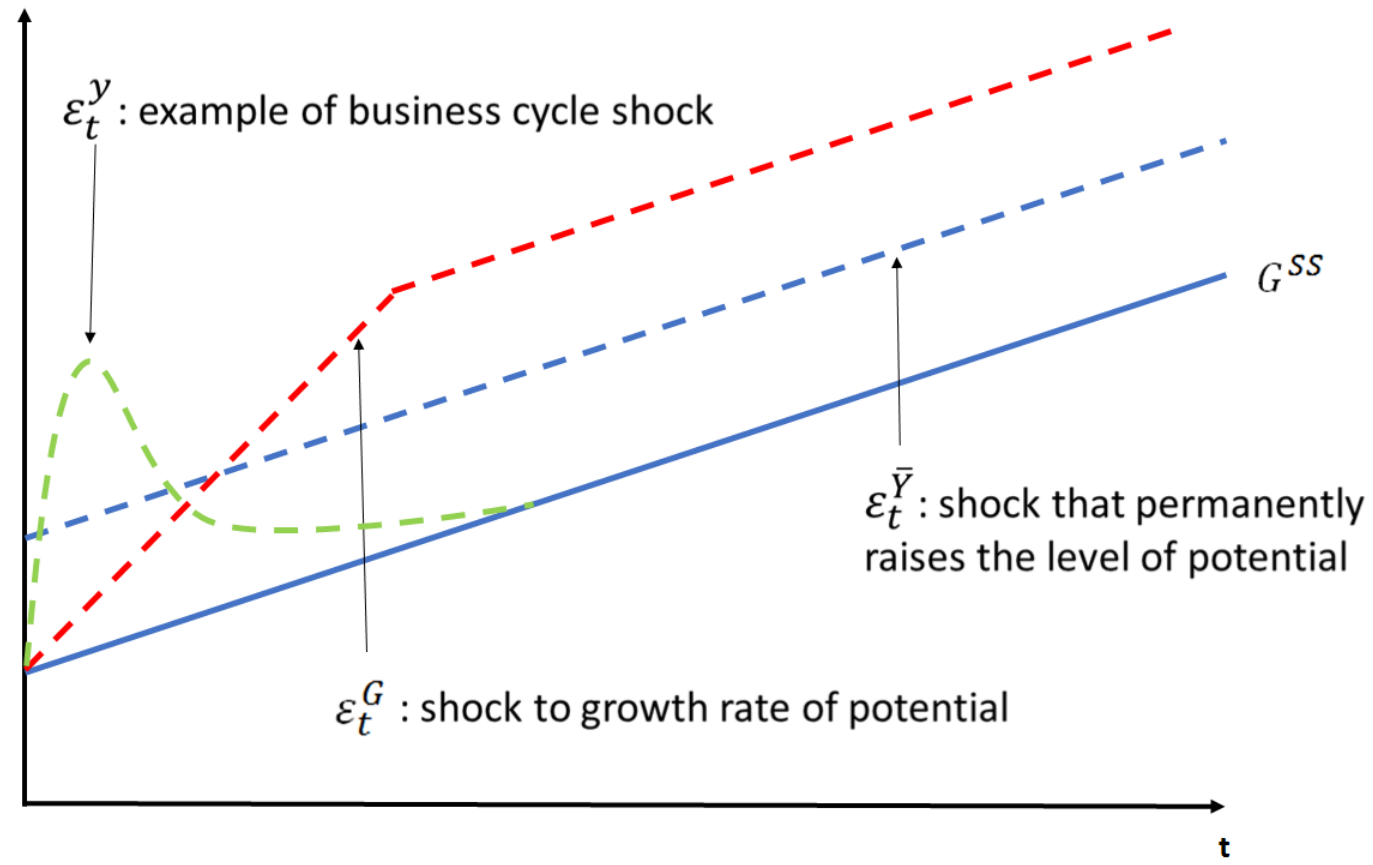

Source: Authors' construction.

All else equal, output would be expected to follow its steady-state path, which is shown above by the solid blue line (which has a slope of $G^{S S}$ ). However, shocks to: the level of potential $\left(\varepsilon_{t}^{\bar{Y}}\right)$; the growth rate of potential $\left(\varepsilon_{t}^{G}\right)$; or the output gap $\left(\varepsilon_{t}^{y}\right)$, can cause output to deviate from this initial steady-state path over time. As shown by the dashed blue line, a

\footnotetext{
${ }^{9}$ An alternative specification for the output gap allows it to follow an $\mathrm{AR}(2)$ process.
} 
shock to the level of potential output in any given period will cause output to be permanently higher (or lower) than its initial steady-state path. Similarly, shocks to the growth rate of potential, illustrated by the dashed red line, can cause the growth rate of output to be higher temporarily, before ultimately slowing back to the steady-state growth rate (note that this would still entail a higher level of output). And, finally, shocks to the output gap would cause only a temporary deviation of output from potential, as shown by the dashed green line.

In order to help identify the three aforementioned output shock terms, a Phillips Curve equation for inflation is added, which links the evolution of the output gap (an unobservable variable) to observable data on inflation according to the process: ${ }^{10}$

$$
\pi_{t}=\lambda E_{t} \pi_{t+1}+(1-\lambda) \pi_{t-1}+\beta y_{t}+\varepsilon_{t}^{\pi}
$$

Equations describing the evolution of unemployment are included to provide further identifying information for the estimation of the output gap:

$$
\begin{aligned}
& \bar{U}_{t}=\left(\tau_{4} \bar{U}^{S S}+\left(1-\tau_{4}\right) \bar{U}_{t-1}\right)+G R O W T H_{-} \bar{U}_{t}+\varepsilon_{t}^{\bar{U}} \\
& \text { GROWTH_} \bar{U}_{t}=\left(1-\tau_{3}\right) G R O W T H_{-} \bar{U}_{t-1}+\varepsilon_{t}^{G R O W T H_{-} \bar{U}} \\
& u_{t}=\tau_{1} y_{t}+\tau_{2} u_{t-1}+\varepsilon_{t}^{u} \\
& u_{t}=\bar{U}_{t}-U_{t}
\end{aligned}
$$

Here, $\bar{U}_{t}$ is the equilibrium value of the unemployment rate (the NAIRU), which is time varying, and subject to shocks $\left(\varepsilon_{t}^{\bar{U}}\right)$ and also variation in the trend $\left(G R O W T H_{-} \bar{U}_{t}\right)$, which is itself also subject to shocks $\left(\varepsilon_{t}^{G R O W T_{-} \bar{U}}\right)$ - this specification allows for persistent deviations of the NAIRU from its steady-state value. Most importantly, we specify an Okun's law relationship wherein the gap between actual unemployment and its equilibrium rate (given by $\left.u_{t}\right)$ is a function of the output gap $\left(y_{t}\right)$.

Finally, we incorporate information from measures of capacity utilization rates in the manufacturing sector to help shed some light on the overall slack in the entire economy at a given point in time.

\footnotetext{
${ }^{10}$ Some recent work suggests that the slope of the Phillips curve relationship $(\beta)$ has flattened over the past several decades (Chapter 3 of the April 2013 World Economic Outlook), whereas other studies suggest that it may have steepened in some countries in recent years (Riggi and Venditti, 2014). Although the methodology in this paper does not allow for time variation in parameter estimates, modest changes in the estimated value of the parameter $\beta$, on its own, do not materially change the estimates of potential output and the output gap.
} 


$$
\begin{aligned}
& \widehat{C A P U}_{t}=C A P U_{t}-\overline{C A P U}_{t} \\
& \overline{C A P U}_{t}=\overline{C A P U}_{t-1}+\text { GROWTH }_{-} \overline{C A P U}_{t}+\varepsilon_{t}^{\overline{C A P U}} \\
& G R O W T H_{-} \overline{C A P U}_{t}=(1-\delta) G R O W T H_{-} \overline{C A P U}_{t-1}+\varepsilon_{t}^{G R O W T H_{-} \overline{C A P U}} \\
& \widehat{C A P U}_{t}=\kappa y+\varepsilon_{t}^{\widehat{C A P U}}
\end{aligned}
$$

In the above, $\overline{C A P U}_{t}$ is the equilibrium value of the capacity utilization rate, which changes over time, and is subject to shocks $\left(\varepsilon_{t}^{\overline{C A P U}}\right)$. The equilibrium capacity utilization rate grows at GROWTH $\overline{C A P U}_{t}$, which is itself also subject to shocks $\left(\varepsilon_{t}^{G R O W T H_{-} \overline{C A P U}}\right)$ - this specification allows for persistent movements in the equilibrium capacity utilization rate. The capacity utilization gap, which is meant to capture the economic slack in the manufacturing sector, should be correlated with the measure of the overall economic slack in the economy $\left(y_{t}\right)$.

Equations (1)-(14) comprise the core of the model for the output gap and potential output. In addition, data on growth and inflation expectations are added to help identify shocks, and to improve the accuracy of the estimates at the end of the sample:

$$
\begin{aligned}
& \pi_{t+j}^{C}=\pi_{t+j}+\varepsilon_{t+j}^{\pi^{C}}, \mathrm{j}=1 \\
& G R O W T H_{t+j}^{C}=G R O W T H_{t+j}+\varepsilon_{t+j}^{G R O W T H^{C}}, \mathrm{j}=1, \ldots, 5
\end{aligned}
$$

For real GDP growth $(G R O W T H)$, the model is augmented with forecasts from Consensus Economics for five years following the end of any particular sample of historical observations. For inflation, expectations data are added for one year following the end of the historical sample period. These equations relate the model-consistent forward expectation for growth and inflation $\left(\pi_{t+j}\right.$ and $\left.G R O W T H_{t+j}\right)$ to observable data on how consensus forecasts expect these variables to evolve over various horizons (one to five years ahead) at any given time (GROWTH $H_{t+j}^{C}$ and $\pi_{t+j}^{C}$ ). The 'strength' of the relationship between the data on consensus and the model's forward expectation is determined by the standard deviation of the error terms $\left(\varepsilon_{t+j}^{\pi^{C}}\right.$ and $\left.\varepsilon_{t+j}^{G R O W T H^{C}}\right)$. In practice, setting non-zero variance of these terms allows consensus data to influence, but not completely override, the model's expectations, particularly at the end of the sample period. In a way, the incorporation of consensus forecasts can be thought as an heuristic approach to blend forecasts from different sources and methods. The resulting impact of this information on the historical estimates of potential and the output gap can be significant, as shown in the following section. 


\section{Estimating The OUTPUt GAP For The United States}

To provide an example of how to apply the multivariate-filter approach, this section presents detailed results for the United States. This version of the multivariate filter uses annual data on real gross domestic product, CPI inflation, the unemployment rate, capacity utilization rate, as well as Consensus Economics multi-year-ahead forecasts for CPI inflation and GDP growth. We will show that the latter data, in particular, are very important for identifying the historical shocks to the output gap, level shocks to potential, as well as the shocks that drive a wedge between underlying growth rate of potential and its steady-state rate. The sources for the data are presented in Appendix Table A1.

The model is estimated as a system using Bayesian estimation techniques. The sample period is 1990 through 2016. Fairly tight priors are imposed on all the parameters except for the standard deviation of shock to inflation $\left(\varepsilon_{t}^{\pi}\right)$ as well as the shock to capacity utilization gap $\left(\varepsilon_{t}^{\widehat{C A P U}}\right)$. The priors are based on existing empirical work. Appendix Table A2 summarizes the priors and posterior estimates for the model's parameters. The parameter for the steadystate GDP growth rate (2.16 percent) is calibrated to the value in the January 2017 Consensus Economics long-term survey of GDP growth in 2027 (which is 10 years ahead). The parameter for the steady-state NAIRU is taken from the latest median of FOMC participants' estimates of the longer-run natural rate of unemployment, which was 4.8 percent. ${ }^{11}$ Both of these parameters act as attractors in the system and will determine where GDP growth and unemployment converge to, over the medium term.

To shed light on the role of the different components of the model, we present each marginal step in the construction of the estimates by gradually expanding the list of observable variables. In what follows, we show that the simple model specified in this paper offers several noteworthy advantages (namely, the theoretical coherence of output-gap estimates and inflation, the transparency of the estimates, as well as its end-of-sample revision properties and the robustness of real-time estimates). However, it is far from perfect, and should not be used mechanically to obtain estimates (nor should any other model).

The output gap estimates based on just using information on GDP and equations (1)-(5) from the preceding section are depicted by the blue line in Figure 2. This is a simple univariate representation of GDP and potential output. However, unlike the HP filter, which assumes that both the output gap and the second difference of potential are white noise processes, equations (1)-(5) provide a more plausible set of stochastic processes. ${ }^{12}$ Recall, the output gap

\footnotetext{
${ }^{11}$ See the Fed's Statement on Longer-Run Goals and Monetary Policy Strategy, amended effective January 31, 2017. This is just one example of expert judgements that can be and should be applied to this simple model when using it in practice.

${ }^{12}$ Estimates of the HP filter can be obtained by minimizing the following objective function: $\sum_{t=1}^{\mathrm{T}}\left(\mathrm{Y}_{\mathrm{t}}-\overline{\mathrm{Y}}_{\mathrm{t}}\right)^{2}+$ $\lambda \sum_{\mathrm{t}=1}^{\mathrm{T}-2}\left[\left(\overline{\mathrm{Y}}_{\mathrm{t}+2}-\overline{\mathrm{Y}}_{\mathrm{t}+1}\right)-\left(\overline{\mathrm{Y}}_{\mathrm{t}+1}-\overline{\mathrm{Y}}_{\mathrm{t}}\right)\right]^{2}$. They can also be obtained by using the Kalman filter to estimate the
} 
is assumed to be positively serially correlated. The level of potential is affected by two types of shocks: a shock that can have a one-off effect on the level of potential; and a shock that can cause persistent deviations of the growth rate of potential from some long run steadystate growth rate.

When using only information from the real GDP series, the univariate filter indicates that output was persistently well above potential during the years prior to the global financial crisis, or, in other words, the estimates of pre-crisis potential output is considerably lower relative to actual output. Filters that included financial cycle considerations (such as Borio, Disyatat, and Juselius (2013) tend to draw a similar picture. The estimates also point to a modest negative output gap after the crisis.

Figure 2. Output Gap Decomposition

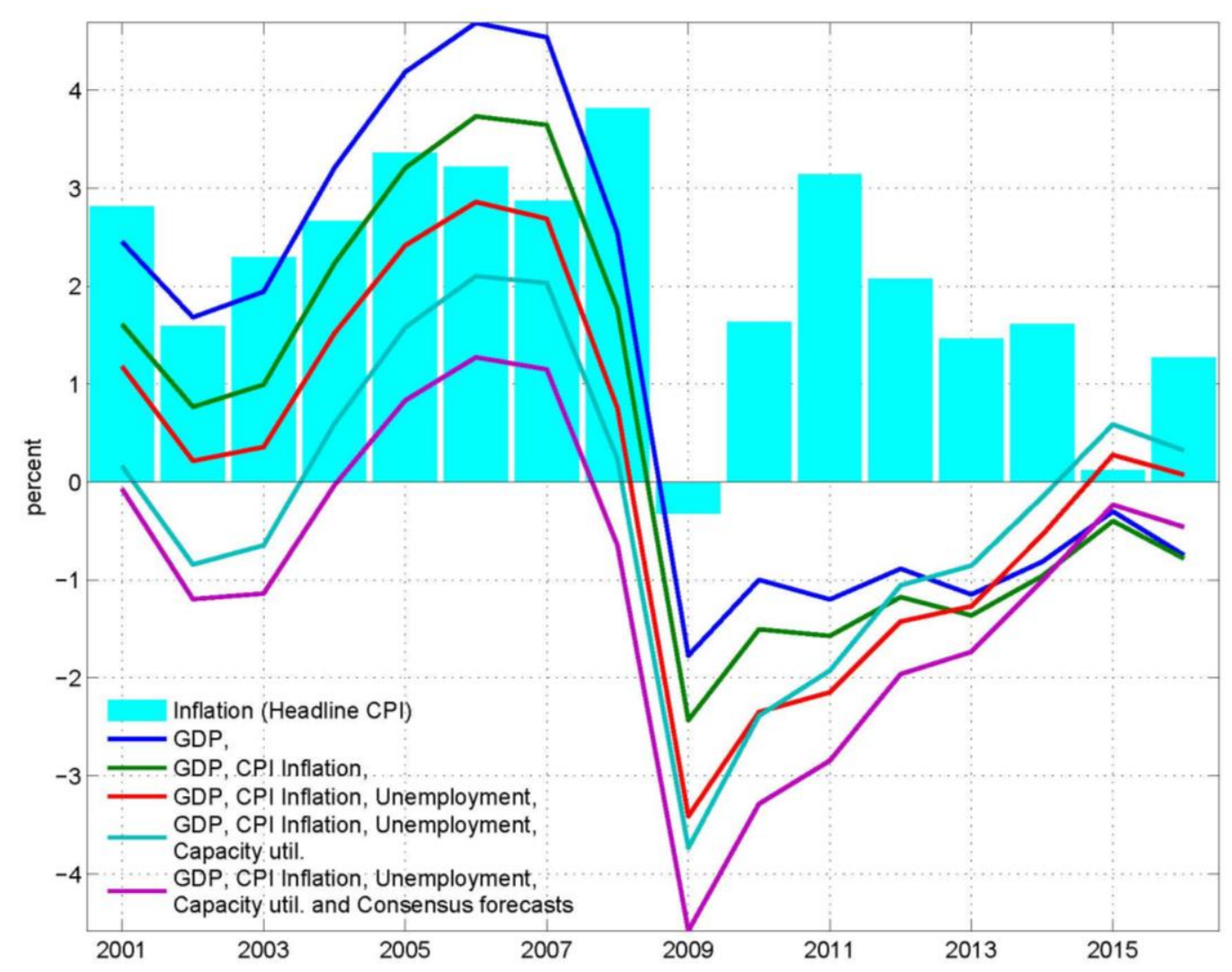

Source: Authors' estimates.

unobservable component $\left(\bar{Y}_{t}\right)$ in the following statistical model: $Y_{t}-\bar{Y}_{t} \sim N\left(0, \sigma_{y}^{2}\right)$ and $\left(\bar{Y}_{t+2}-\bar{Y}_{t+1}\right)-$ $\left(\overline{\mathrm{Y}}_{\mathrm{t}+1}-\overline{\mathrm{Y}}_{\mathrm{t}}\right) \sim \mathrm{N}\left(0, \sigma_{\overline{\mathrm{Y}}}^{2}\right)$. The code and related training material for comparing these two sets of results can be found on www.douglaslaxton.org. 
The addition of inflation to the list of observable variables and the Phillips Curve (equation (6)) suggests slightly less excess demand in the pre-crisis period, given that inflation was not very elevated (dark green line). In the post-crisis period, the inclusion of inflation points to more economic slack, which results from the structure of the filter, where below-target inflation rates are associated with negative output gaps, all else equal. Of course, as practitioners we may not agree with this simple mechanical assessment of the filter, which would motivate the addition of judgment to help condition these estimates at the end of the sample.

The additions of model structure for unemployment (equations (7)-(10)) and the unemployment data produce the estimates depicted by the red line. Adding unemployment to the model results in significantly larger estimates of slack following the global financial crisis. This reflects a very tight correlation between the output gap and the unemployment gap (Figure 3) which helps to identify periods of large slack during periods of high unemployment, such as during the period after the global financial crisis.

Figure 3. Output Gap, Unemployment Gap, Capacity Utilization Gap, and Inflation

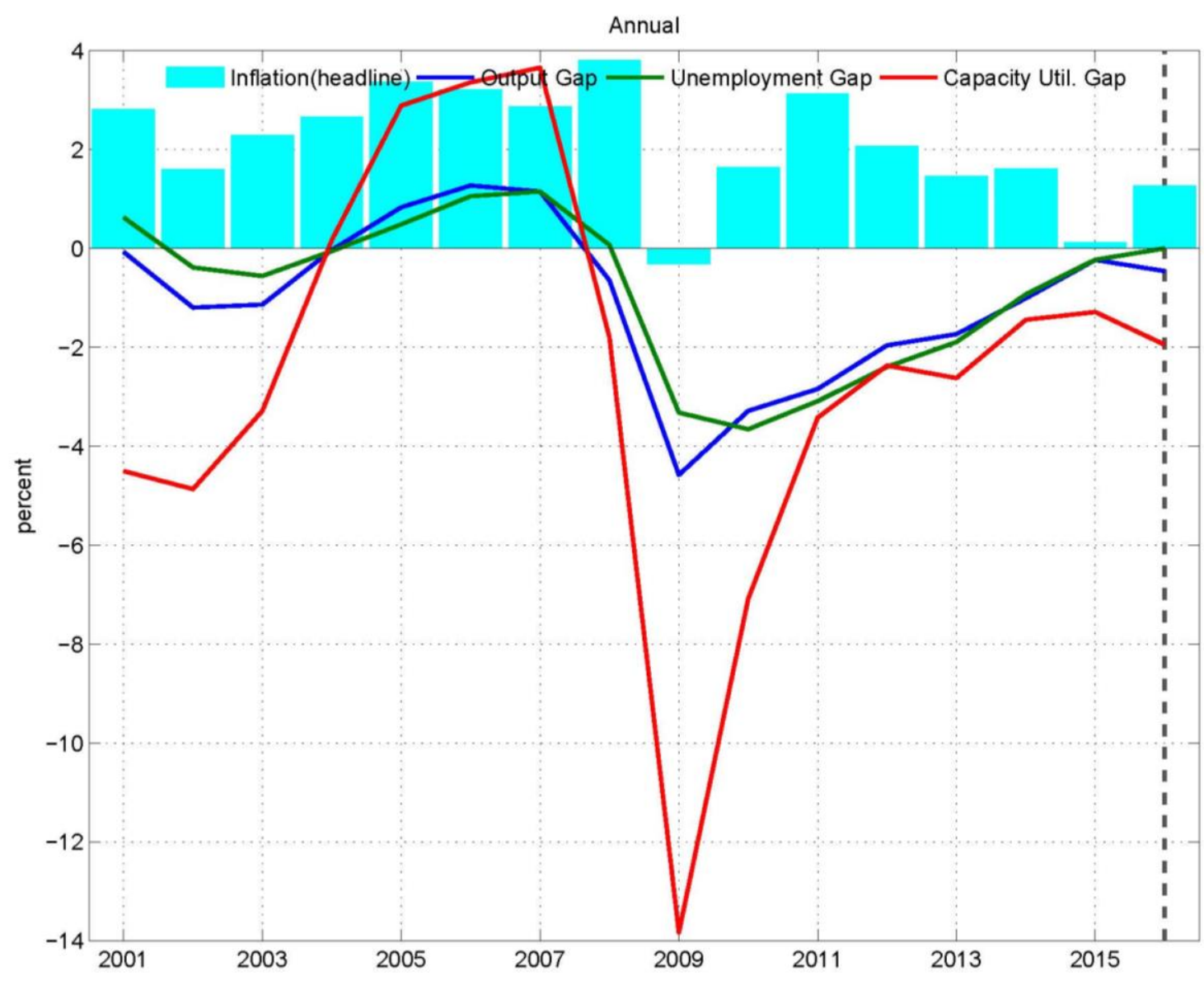

Source: Authors' estimates. 
Adding capacity utilization further helps the model identify the cyclical conditions of the economy. Capacity utilization, which is one part of resource utilization, measures the intensity with which capital is used in the economy. There is rich evidence showing that the capacity utilization rate varies over the business cycle. Therefore, failing to account for it might lead us to underestimate (overestimate) total factor productivity when utilization is low (high).

Capacity utilization surveys capture the extent to which manufacturing firms are operating above or below capacity. But because they are based on simple engineering concepts of capacity they might fail to capture structural shifts which affect the level of economic capacity itself. For example, when a product is no longer economically viable, survey measures of capacity utilization in that industry might be reported as very low to the extent that the production lines are unused, when effectively the stock of capital in that industry might not be contributing to potential output.

With the additional information from capacity utilization (teal line), the estimation results point to slightly larger slack in the economy at the nadir of the crisis, and a much faster closing of the output gap since then. This reflects the sharp rebound in the capacity utilization after the crisis. Several studies illustrate the importance of accounting for resource utilization when estimating potential output. Alichi (2015) argues that the inclusion of capacity utilization is crucial to obtain a reliable measure of potential output for the U.S., particularly in periods when the labor gap and capacity utilization give opposing indications about the degree of slack in the economy. Fernald (2014) estimates a comprehensive measure of resource utilization for the U.S. which also captures labor utilization. This measure suggests that the utilization gap was nearly closed in 2013, in contrast to the evidence based solely on simple capacity utilization surveys.

Adding consensus medium-term forecasts for GDP growth and near-term forecasts for CPI inflation produces the pink line. This results in even larger and more persistent negative output gaps after the global financial crisis. This seems to reflect the fact that consensus forecasts were fairly strong for most of the past decade, with the exception of the crisis period, and have been revised down significantly since the crisis - the filter interprets this as evidence that the observed decline in growth during the crisis had important cyclical and structural elements.

Overall, there is a clear policy picture in the final estimates. In particular, the U.S. economy was growing slightly above its potential before the global financial crisis, and a modest tightening in monetary policy conditions might have been warranted. The crisis plunged the economy into a deep recession, opening up significant slack in both the goods market and labor market. The manufacturing sector was heavily affected, reflected by high under-utilized capacity. The recovery of the economy started quickly after the crisis, but then proceeded 
much more slowly than in typical business cycles. Eight years after the crisis, the amount of slack in the economy has almost diminished, but there are still underutilized resources, which seems consistent with the current moderate inflation. With the benefits of hindsight, the estimates suggest that the fiscal stimulus applied during the early phases of recovery could have been withdrawn much more slowly.

We compare the results from the multivariate filter with the estimates from other international organizations (see Table 1). The estimates of potential that come out of the filter are broadly comparable with that of other institutions. However, the filter's estimate of potential growth decelerated earlier than that from other institutions at the beginning of the global financial crisis. The estimates of potential growth and the output gap from these institutions have been close to the filter's results subsequently. The model also shows that the economic recovery since the 2010 reflects a gradual and steady pick-up in potential growth, which is not fully captured by estimates from other international organizations.

Table 1. Comparison of Results

\begin{tabular}{|c|c|c|c|c|c|c|c|c|c|c|c|c|c|c|c|c|}
\hline & 2001 & 2002 & 2003 & 2004 & 2005 & 2006 & 2007 & 2008 & 2009 & 2010 & 2011 & 2012 & 2013 & 2014 & 2015 & 2016 \\
\hline \multicolumn{17}{|c|}{ Potential GDP growth (Percent) } \\
\hline $\mathrm{CBO}$ & 3.6 & 3.3 & 2.9 & 2.4 & 2.2 & 2.2 & 2.2 & 2.0 & 1.5 & 1.1 & 1.1 & 1.4 & 1.5 & 1.6 & 1.1 & 1.6 \\
\hline EO & 3.1 & 2.5 & 2.2 & 2.1 & 2.3 & 2.3 & 2.3 & 2.1 & 1.9 & 1.7 & 1.6 & 1.7 & 1.6 & 1.6 & 1.6 & 1.5 \\
\hline \multicolumn{17}{|l|}{ IMF } \\
\hline WEO & 3.3 & 2.9 & 2.6 & 2.5 & 2.4 & 2.3 & 2.2 & 2.2 & 1.9 & 1.2 & 1.2 & 1.3 & 1.4 & 1.7 & 1.7 & 1.6 \\
\hline \multicolumn{17}{|c|}{ Output gap (Percent) } \\
\hline $\mathrm{CBO}$ & -0.5 & -2.0 & -2.1 & -0.7 & 0.4 & 0.8 & 0.4 & -1.8 & -6.0 & -4.7 & -4.3 & -3.4 & -3.3 & -2.6 & -1.2 & -1.2 \\
\hline \multicolumn{17}{|l|}{ OECD } \\
\hline EO & 0.5 & -0.3 & 0.1 & 1.5 & 2.6 & 3.0 & 2.6 & 0.1 & -4.4 & -3.5 & -3.5 & -2.9 & -2.9 & -2.2 & -1.2 & -1.2 \\
\hline \multicolumn{17}{|l|}{ IMF } \\
\hline WEO & 1.2 & 0.1 & 0.3 & 1.6 & 2.6 & 2.9 & 2.5 & 0.0 & -4.6 & -3.4 & -3.1 & -2.2 & -1.9 & -1.3 & -0.4 & -0.5 \\
\hline \multicolumn{17}{|c|}{ Natural rate of unemployment (Percent) } \\
\hline $\mathrm{CBO}$ & 5.0 & 5.0 & 5.0 & 5.0 & 5.0 & 5.0 & 4.9 & 4.9 & 5.0 & 5.1 & 5.1 & 5.1 & 5.0 & 4.9 & 4.8 & 4.7 \\
\hline \multicolumn{17}{|l|}{ OECD } \\
\hline EO & 5.2 & 5.2 & 5.3 & 5.3 & 5.3 & 5.3 & 5.3 & 5.2 & 5.2 & 5.2 & 5.1 & 5.1 & 5.0 & 5.0 & 4.9 & 4.9 \\
\hline \multicolumn{17}{|l|}{ IMF } \\
\hline WEO & 5.0 & 5.0 & 5.0 & 5.0 & 5.0 & 5.0 & 5.0 & 5.5 & 6.0 & 6.5 & 6.3 & 6.1 & 6.0 & 5.6 & 5.3 & 5.0 \\
\hline MVF & 5.4 & 5.4 & 5.4 & 5.5 & 5.6 & 5.7 & 5.8 & 5.9 & 6.0 & 6.0 & 5.8 & 5.7 & 5.5 & 5.2 & 5.0 & 4.9 \\
\hline \multicolumn{17}{|c|}{ Unemployment gap (Percent) } \\
\hline CBO & 0.3 & -0.8 & -1.0 & -0.5 & -0.1 & 0.4 & 0.3 & -0.9 & -4.3 & -4.5 & -3.8 & -3.0 & -2.4 & -1.3 & -0.5 & -0.1 \\
\hline \multicolumn{17}{|l|}{ OECD } \\
\hline EO & 0.4 & -0.6 & -0.7 & -0.2 & 0.2 & 0.7 & 0.7 & -0.6 & -4.1 & -4.5 & -3.8 & -3.0 & -2.4 & -1.2 & -0.3 & 0.0 \\
\hline \multicolumn{17}{|l|}{ IMF } \\
\hline WEO & 0.3 & -0.8 & -1.0 & -0.5 & -0.1 & 0.4 & 0.4 & -0.3 & -3.3 & -3.1 & -2.6 & -2.0 & -1.4 & -0.5 & 0.0 & 0.1 \\
\hline
\end{tabular}

Source: OECD Economic Outlook (EO) November 2016; CBO January 2017; IMF World Economic Outlook (WEO) Live, March 2017; authors' estimates. 


\section{Uncertainty in Estimating the OUtput Gap and Potential}

Potential output and the output gap are not variables that can be observed- they can only be estimated, and these estimates are subject to varying degrees of imprecision, depending on the technique used and the amount of information available when the estimates are constructed. To assess the robustness of the MVF estimates of potential, we construct confidence bands for the MVF approach specified in this paper and then compare them to confidence bands for a simple HP filtration of GDP. These confidence bands measure the uncertainty inherent in the model's estimates of the latent variables, and are not intended to capture model or parameter uncertainty, which are broader concepts beyond the scope of this exercise.

The objective of this exercise is to compare the performance of the HP filter and the multivariate filter, under various assumptions about the relative importance of supply and demand shocks. To do this, we need benchmark estimates for the parameters of the model. These estimates are obtained from the posterior estimation of the full structural model described in the paper. These estimates are summarized in Appendix Table A2 and A3.

As we have discussed in Section IV, the econometric literature on the uncertainty about the sources of demand and supply shocks provides various calibrations for the relative contribution of supply and demand components to output movements. We take our estimates from the mode of the posterior distribution as the benchmark case, where demand shocks can explain approximately 87 percent of total output variations. We consider two other alternative cases where the ratio is 98 percent and 72 percent, respectively. These two alternative cases use the same equations and parameter estimates as the benchmark caseexcept, of course, different standard deviations for supply and demand shocks. Table 2 compares the standard deviations of the shocks for all three cases.

Table 2. Standard Deviation of Supply and Demand Shocks

\begin{tabular}{ccccc}
\hline Shocks & Parameters & Benchmark & Alternative (I) & Alternative (II) \\
\hline Supply Shock & $\sigma\left(\varepsilon^{\bar{Y}}\right)$ & 0.1 & 0.1 & 0.4 \\
& $\sigma\left(\varepsilon^{G}\right)$ & 0.2 & 0.1 & 0.4 \\
\hline Demand Shock & $\sigma\left(\varepsilon_{t}^{y}\right)$ & 0.8 & 1.0 & 1.0 \\
\hline $\begin{array}{c}\text { Percent of Demand } \\
\text { Shock }\end{array}$ & $\sigma^{2}(\Delta y)$ & & & \\
\hline$\sigma^{2}(\Delta Y)$ & $\approx 87$ percent & $\approx 98$ percent & $\approx 72$ percent \\
\hline
\end{tabular}

Note: $\sigma$ represents standard deviation.

Source: Author's calculation. 
A Monte Carlo simulation of 1,000 draws of all variables from the full structural model is conducted. We simulate for a sufficiently long period (1,000 years). To alleviate the burn-in bias, the first 500 years of simulation are discarded.

The HP filter with a signal-noise ratio $(\lambda)$ of 6.25 is applied to the GDP observables in each of the 1,000 samples. We compute the deviations of the HP filter estimates of the potential output and output gap from the assumed true paths, and report the 95 -percent confidence bands in Figure 4. Similar steps are implemented for the multivariate filter to allow a fair comparison between the two methods. The multivariate filter is applied to all the observables in each sample, and the 95-percent confidence bands of the deviations of the estimates of potential output and output gap from their assumed true paths are plotted.

\section{Figure 4. 95-Percent Confidence Bands for Estimates of Potential Growth}
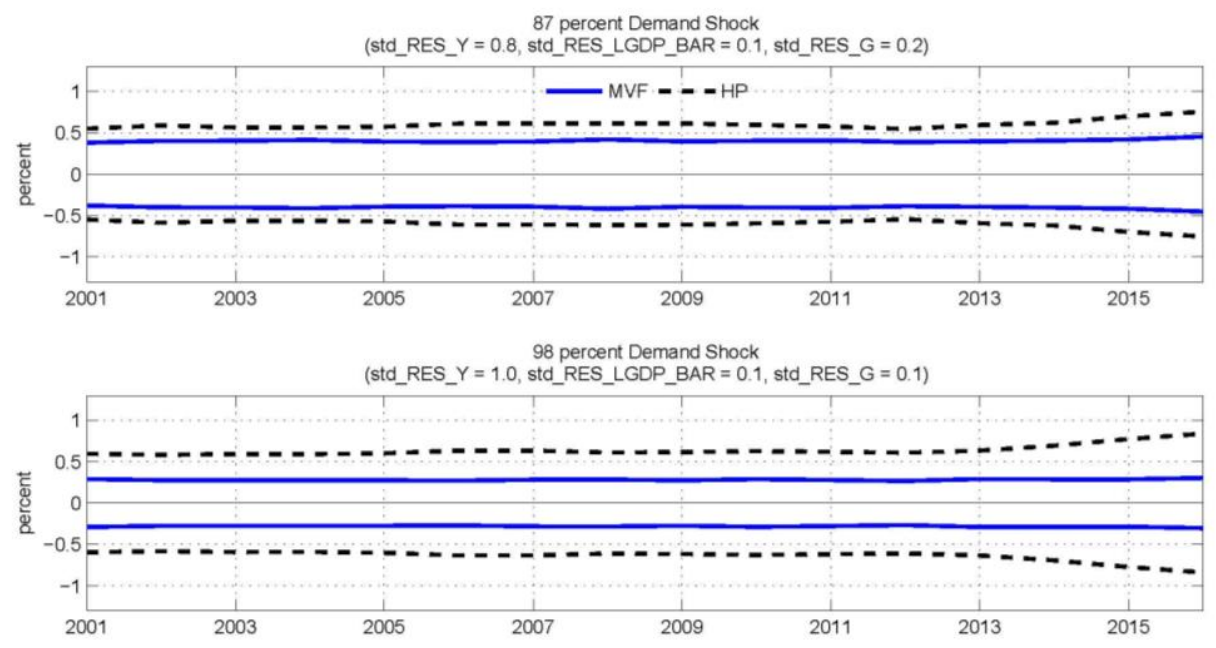

72 percent Demand Shock

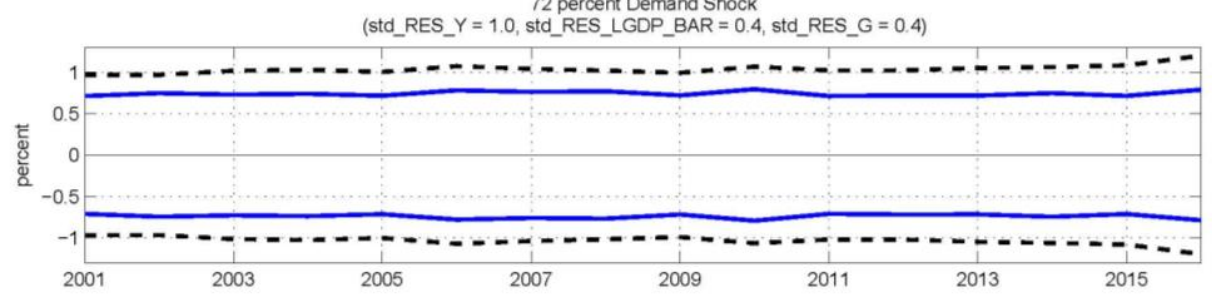

Source: Authors' estimates.

Each panel shows results using three different calibrations for the relative variance of supply and demand shocks. The top one is the baseline calibration of the MVF used in this paper (where demand shocks explain approximately 87 percent of total output variations), and showing alternative calibrations serves as a robustness check to ensure that the improved fit of the MVF relative to the HP filter is not a function of these relative variances. As shown in 
the figures, irrespective of the assumed relative incidence of these shocks, the estimates of potential and the output gap coming from the MVF are subject to less uncertainty than are those from an HP filter. This result follows from the fact that more identifying information is used in the MVF than in a simple univariate filter. ${ }^{13}$

\section{Figure 5. 95-Percent Confidence Bands for Estimates of Output Gap}
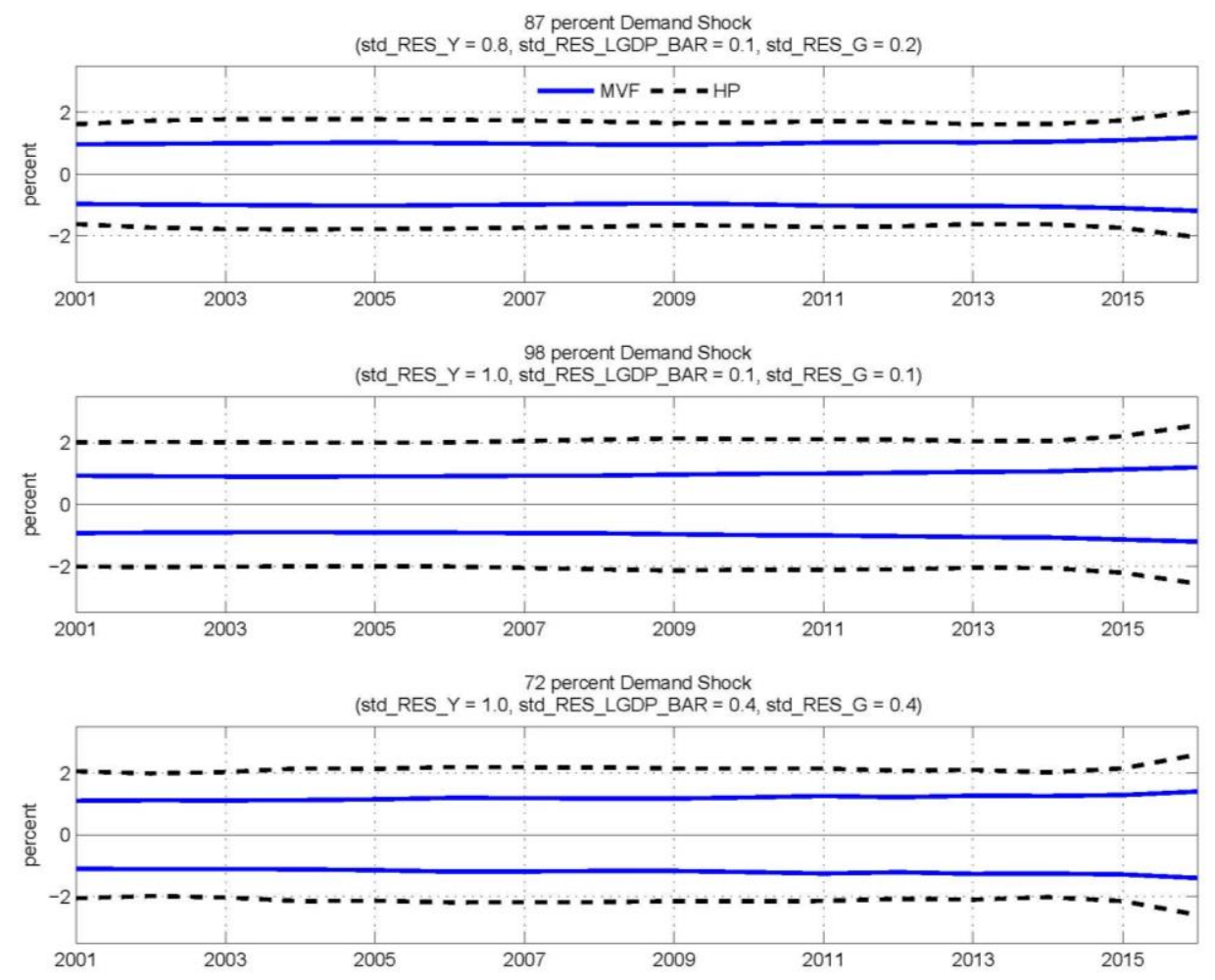

Source: Authors' estimates.

Real-time estimates coming from the MVF are also less prone to revision than are estimates derived from an HP filter. In Figure 6, quasi-real-time ${ }^{14}$ estimates of potential output over the past 20 years are plotted.

\footnotetext{
${ }^{13}$ The degree to which the MVF estimates outperform those from the simple HP filter does vary by country, and depends on the strength of the relationship between the output gap and inflation/unemployment in a given economy.

${ }^{14}$ These estimates are constructed by sequentially estimating potential output in each year, using only the data available as of that date. For example, the quasi-real-time estimates of potential in 2007 (for both HP and MVF) would have used data from the beginning of the sample through 2007 only. The estimates are 'quasi' real-time in the sense that actual vintage data are not used for this exercise (but rather only currently-available data, which have been revised over time).
} 
Figure 6. Potential Growth Estimates as the Sample is Extended
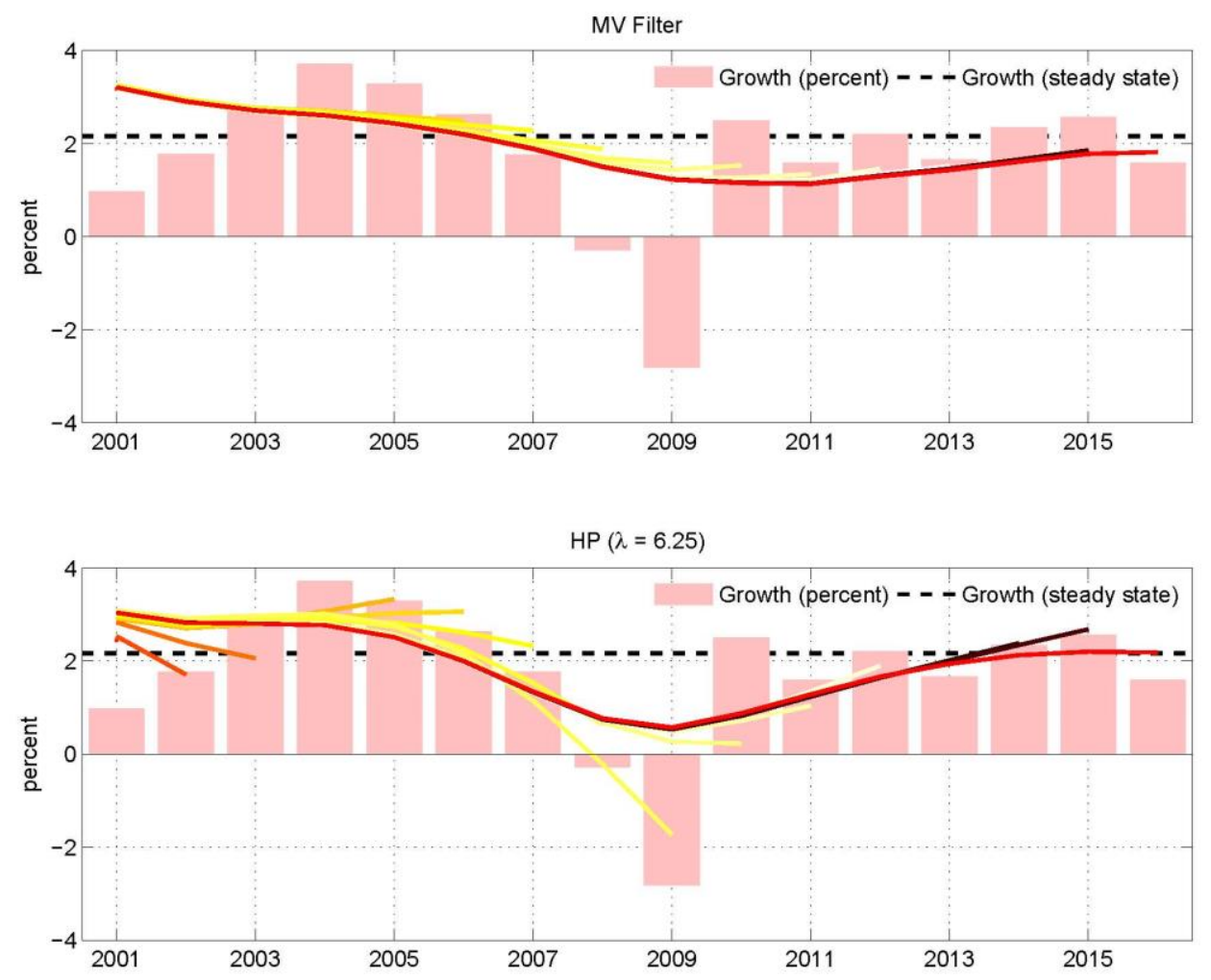

Source: Authors' estimates.

\section{Conclusion}

The methodology presented in this paper draws on previous work applying multivariate filters to the estimation of potential output. By embedding the structural relationship between inflation, unemployment, capacity utilization, and the output gap, this class of models produces estimates of potential output and economic slack which are intuitive and consistent with basic economic theory. The innovations in this paper are twofold: first, this approach is particularly useful in estimating potential output in the U.S. where the availability of many other sources of information helps to fine-tune the filter's estimate. And, second, data on growth expectations have been added in order to help address (though not completely alleviate) the end-of-sample problem. As shown in the preceding section, estimates of potential obtained using this model are more robust than those resulting from HP-filtering techniques. Still, the end-of-sample problem remains an issue, particularly around turning points in the business cycle, which motivates the use of additional information taken from outside the model by practitioners when using the results to guide policy. 
Future work can focus on extending the methodology to other countries, and experimenting with alternate measures of inflation, such as core inflation or PCE inflation in the case of the United States. In addition, the results will be investigated further to gauge whether there are important commonalities in the evolution of potential output in the pre- and post-crisis periods across countries - this will be done by decomposing the existing results using a production-function approach. The approach could also be extended by explicitly incorporating other sources of information into the multivariate filter, such as measures of capital services. 


\section{REFERENCES}

Abiad, A., R. Balakrishnan, P. Koeva Brooks, D. Leigh, and I. Tytell, "What's the Damage? Medium-term Output Dynamics After Banking Criese," IMF Working Paper No. $09 / 245$.

Alberoa, E., A. Estrada, and D. Santabarbara, 2013, "Growth Beyond Imbalances. Sustainable Growth Rates and Output Gap Reassessment," Banco de Espana Documentos de Trabajo No. 1313.

Alichi, A., 2015, "A New Methodology for Estimating the Output Gap in the United States," IMF Working Paper No. 15/144.

Alichi, A., O. Bizimana, S. Domit, E. Fernández-Corugedo, D. Laxton, K. Tanyeri, H. Wang, and F. Zhang, 2015, "Multivariate Filter Estimation of Potential Output for the Euro Area and the United States," IMF Working Paper No. 15/253.

Alichi, A., H. Chen, K. Clinton, C. Freedman, M. J. Johnson, O. Kamenik, T. Kisinbay, and D. Laxton, 2009, "Inflation Targeting Under Imperfect Policy Credibility,” IMF Working Paper No. 09/94.

Argov, E., N. Epstein, P. Karam, D. Laxton, and D. Rose, 2007, "Endogenous Monetary Policy Credibility in a Small Structural Model of Israel”, IMF Working Paper No. 07/207.

Bank of Canada, 2009, Monetary Policy Report, July 2009.

Basistha, A. and R. Startz, 2008, "Measuring the NAIRU with Reduced Uncertainty: A Multiple-Indicator Common-Cycle Approach," The Review of Economics and Statistics, 2008, vol. 90, issue 4, pages 805-811.

Benes, J., K. Clinton, R. Garcia-Saltos, M. Johnson, D. Laxton, P. Manchev, and T. Matheson, 2010, "Estimating Potential Output with a Multivariate Filter," IMF Working Paper No. 10/285.

Benes, J., M. Kumhof, and D. Laxton. 2014a, "Financial Crises in DSGE Models: Selected Applications of MAPMOD.” IMF Working Paper No. 14/56.

Benes, J., M. Kumhof, and D. Laxton. 2014b, "Financial Crises in DSGE Models: A Prototype Model.” IMF Working Paper No. 14/57.

Blagrave, P., R. Garcia-Saltos, D. Laxton, and F. Zhang, “A Simple Multivariate Filter for Estimating Potential Output,” IMF Working Paper No. 15/79. 
Boone, L., M. Juillard, D. Laxton, and P. N'Diaye, 2002, "How Well Do Alternative TimeVarying Models of the NAIRU Help Policymakers Forecast Unemployment?”, unpublished draft available from authors.

Borio, C., P. Disyatat, and M. Juselius, 2013, "Rethinking Potential Output: Embedding Information about the Financial Cycle," BIS Working paper No. 404.

Clark, P., D. Laxton, and D. Rose, 1995, "Capacity Constraints, Inflation and the Transmission Mechanism: Forward-Looking Versus Myopic Policy Rules,” IMF Working Paper No. 95/75.

Clark, P., D. Laxton, and D. Rose, 2001, “An Evaluation of Alternative Monetary Policy Rules in a Model with Capacity Constraints," Journal of Money Credit and Banking, Vol. 33, No. 1 (February), pp. 42-64.

D’Auria, F, C. Denis, K. Havik, K. McMorrow, C. Planas, R. Raciborski, W. Roger, A. Rossi, 2010, "The production function methodology for calculating potential growth rates and output gaps," European Commission Economic Papers No. 420, July.

Debelle, G., and D. Laxton, 1997, "Is the Phillips Curve Really a Curve? Some Evidence for Canada, The United Kingdom and the United States," Staff Papers, International Monetary Fund, Vol. 44, No. 2, June, pp. 249-82.

Fernald, J. G., 2014, “A quarterly utilization-adjusted series on total factor productivity”, Federal Reserve Bank of San Francisco, Working Paper 2012-19, March 2014.

Fleischman, C. A. and J. M. Roberts, 2011, "From Many Series, One Cycle: Improved Estimates of the Business Cycle from a Multivariate Unobserved Components Model," FEDS Working Papers 2011-46.

Hodrick, R.J., and E.C. Prescott, 1997, "Post-War U.S. Business Cycles: An Empirical Investigation," Journal of Money, Credit and Banking, Vol. 29(1), pp. 1-16.

Isard, P., D. Laxton, and A. Eliasson, 1999, "Simple Monetary Policy Rules Under Model Uncertainty," International Tax and Public Finance, Vol. 6, pp. 537-577.

Juillard, M., O. Kamenik, M. Kumhof, and D. Laxton, 2007, "Measures of Potential Output from an Estimated DSGE Model of the United States," paper presented at a workshop on Issues in Measuring Potential Output, Ankara Turkey, January 16.

Kuttner, K. N., 1994, "Estimating Potential Output as a Latent Variable," Journal of Business and Economic Statistics, Vol. 12, pp. 361-68.

Laxton, D., N. Ricketts, and D. Rose, 1993, "Uncertainty, Learning and Policy Credibility, Economic Behavior and Policy Choice Under Price Stability," Proceedings of a Conference held at the Bank of Canada, 30-31 October. 
Laxton, D., D. Rose, and R. Tetlow, 1993, "Problems in Identifying Nonlinear Phillips Curves: Some Further Consequences of Mismeasuring Potential Output," Bank of Canada Working Paper No. 93/6.

Laxton, D. and R. Tetlow, 1992, "A Simple Multivariate Filter for the Measurement of Potential Output," Technical Report No. 59 (Ottawa: Bank of Canada).

Okun, A.M., 1962, "Potential GNP: Its Measurement and Significance," in Proceedings of the Business and Economic Statistics Section, pp. 98-104 (Washington: American Statistical Association).

Rabanal, P., and M.T. Sanjani, 2015, "Financial Factors: Implications for Output Gaps,” IMF Working Paper No. 15/153.

Riggi, M. and F. Venditti, 2014, "Surprise! Euro Area Inflation Has Fallen," Bank of Italy Occasional Paper No. 237.

Vetlov, I., T. Hledik, M. Jonsson, H. Kucsera, and M. Pisani, 2011, "Potential Output in DSGE Models,” ECB Working Paper Series No. 1351. 


\section{APPENDIX}

Table A1. Data Sources

\begin{tabular}{ll}
\hline Indicator & Source \\
\hline Inflation Expectations & Consensus Economics \\
Gross Domestic Product Growth Expectations (Constant Prices) & Consensus Economics \\
Gross Domestic Product (Constant Prices) & IMF, World Economic Outlook Database \\
CPI Inflation & IMF, World Economic Outlook Database \\
Unemployment Rate & IMF, World Economic Outlook Database \\
Capacity Utilization & Federal Reserve \\
\hline
\end{tabular}

Table A2. Estimated Parameters

\begin{tabular}{|c|c|c|c|c|c|}
\hline Parameter & $\begin{array}{l}\text { Prior } \\
\text { Mode }\end{array}$ & $\begin{array}{c}\text { Prior } \\
\text { Standard } \\
\text { Error }\end{array}$ & $\begin{array}{l}\text { Lower } \\
\text { Bound }\end{array}$ & $\begin{array}{l}\text { Upper } \\
\text { Bound }\end{array}$ & $\begin{array}{l}\text { Posterior } \\
\text { Mode }\end{array}$ \\
\hline$\beta$ & 0.250 & 0.100 & 0.050 & 3.000 & 0.082 \\
\hline$\lambda$ & 0.250 & 0.100 & 0.050 & 0.990 & 0.311 \\
\hline$\phi$ & 0.600 & 0.100 & 0.100 & 0.990 & 0.671 \\
\hline$\theta$ & 0.300 & 0.010 & 0.050 & 0.900 & 0.291 \\
\hline$\delta$ & 0.250 & 0.100 & 0.050 & 0.990 & 0.143 \\
\hline$\kappa$ & 2.000 & 0.500 & 1.000 & 10.000 & 2.162 \\
\hline$\tau_{1}$ & 0.300 & 0.100 & 0.050 & 0.990 & 0.522 \\
\hline$\tau_{2}$ & 0.300 & 0.100 & 0.050 & 0.990 & 0.408 \\
\hline$\tau_{3}$ & 0.100 & 0.050 & 0.050 & 0.990 & 0.120 \\
\hline$\tau_{4}$ & 0.100 & 0.050 & 0.050 & 0.990 & 0.120 \\
\hline$\sigma\left(\varepsilon_{t}^{y}\right)$ & 0.800 & 0.010 & 0.005 & 3.000 & 0.804 \\
\hline$\sigma\left(\varepsilon_{t}^{\bar{Y}}\right)$ & 0.100 & 0.010 & 0.005 & 3.000 & 0.101 \\
\hline$\sigma\left(\varepsilon_{t}^{G}\right)$ & 0.200 & 0.010 & 0.005 & 3.000 & 0.221 \\
\hline$\sigma\left(\varepsilon_{t}^{\pi}\right)$ & 0.250 & 0.200 & 0.005 & 3.000 & 0.683 \\
\hline$\sigma\left(\varepsilon_{t}^{u}\right)$ & 0.500 & 0.010 & 0.005 & 3.000 & 0.498 \\
\hline$\sigma\left(\varepsilon_{t}^{\bar{U}}\right)$ & 0.100 & 0.010 & 0.005 & 3.000 & 0.100 \\
\hline$\sigma\left(\varepsilon_{t}^{g \bar{U}}\right)$ & 0.100 & 0.010 & 0.005 & 3.000 & 0.099 \\
\hline$\sigma\left(\varepsilon_{t}^{\overline{C A P U}}\right)$ & 0.200 & 0.010 & 0.050 & 0.990 & 0.200 \\
\hline$\sigma\left(\varepsilon_{t}^{G R O W T H_{-} \overline{C A P U}}\right)$ & 0.200 & 0.010 & 0.050 & 0.990 & 0.202 \\
\hline$\sigma\left(\varepsilon_{t}^{\widehat{C A P U}}\right)$ & 4.000 & 1.000 & 1.000 & 10.000 & 2.271 \\
\hline
\end{tabular}

Note: $\sigma$ represents the standard deviation. 
Table A3. Calibrated Parameters

\begin{tabular}{cc}
\hline Parameter & Value \\
\hline$G^{S S}$ & 2.16 \\
$\bar{U}^{s S}$ & 4.80 \\
$\sigma\left(\varepsilon_{t+j}^{\pi^{C}}\right), j=1$ & 1.00 \\
$\sigma\left(\varepsilon_{t+j}^{G R O W T H^{C}}\right), j=1, \ldots 5$ & 1.50 \\
\hline
\end{tabular}

Note: $\sigma$ represents the standard deviation. 